\title{
CENÁRIO DOS CURSOS A DISTÂNCIA DE SECRETARIADO NO BRASIL.
}

\section{THE DISTANCE EDUCATION OVERVIEW IN UNDERGRADUATE SECRETARIAT COURSES IN BRAZIL}

\section{Bruna Beatriz Locks}

Mestranda em Administração da Universidade Regional de Blumenau - FURB, Santa Catarina (Brasil).E-mail: byalocks@gmail.com

\section{Thaíse Caroline Milbratz}

Mestranda em Administração da Universidade Regional de Blumenau - FURB, Santa Catarina, (Brasil).E-mail: tcmilbratz@yahoo.com.br

\section{Vilmar Siewert Junior}

Mestrando em Administração da Universidade Regional de Blumenau - FURB, Santa Catarina (Brasil).E-mail: siewert.vilmar@outlook.com

\section{Maria José Carvalho de Souza Domingues}

Doutorado em Engenharia de Produção pela Universidade Federal de Santa Catarina - UFSC, Santa Catarina (Brasil). E-mail: mjcsd2008@gmail.com 


\title{
CENÁRIO DOS CURSOS A DISTÂNCIA DE SECRETARIADO NO BRASIL.
}

\section{RESUMO}

Devido a carência de estudos científicos sobre o ensino a distância na área de Secretariado, percebeu-se uma lacuna na verificação do atual cenário do curso nesta modalidade no país. Desta maneira, o objetivo deste estudo foi elaborar um panorama dos cursos de Secretariado, e suas variantes (Secretariado Executivo, Secretariado Executivo Bilíngue e Secretariado Executivo Trilíngue), na modalidade a distância - EaD - e assim, analisar as tendências nos rumos do curso no Brasil. Em termos metodológicos, a pesquisa apresenta abordagem quantitativa, sendo que os principais procedimentos de investigação se deram a partir de dados secundários, obtidos no portal do MEC (2015), Enade (2012) e INEP (2014). Os principais resultados remetem a uma crescente expansão dos cursos tecnológicos de Secretariado a distância no país, uma vez que os cursos na modalidade presencial vêm enfrentando uma redução em sua oferta. Outro resultado levantado no estudo refere-se as redes de distribuição, formadas pelas IES que ofertam o curso nas regiões do país, apontando para uma dominação de instituições privadas e com sede nas regiões Sul e Sudeste do Brasil.

Palavras-chave: Secretariado Executivo. Curso Superior. Educação a Distância. Brasil.

\section{THE DISTANCE EDUCATION OVERVIEW IN UNDERGRADUATE SECRETARIAT COURSES IN BRAZIL}

\begin{abstract}
Due to the lack of scientific studies on distance education in the Secretariat field, it has been noticed a gap on verifying the current course scenario in the country. Thus, the main objective of this study was to assemble the Executive Secretariat undergraduate courses panorama, and their variants (Executive Secretary, Bilingual Executive Secretary and Trilingual Executive Secretary), in distance modality - distance education - and then, analyze this course trends in Brazil. In methodological terms, the research presents a quantitative approach, and the main investigative procedures were based on secondary data obtained from the MEC website (2015), Enade (2012) and INEP (2014). The core results are given due to a growing expansion of distance learning technology courses in the country, once the regular bachelor's degree in face-to-face modality are under significant offer reduction. Another point raised in the study refers to the distribution networks established by institutions that offer the course in the regions of the country, pointing to a control from private institutions based in the South and Southeast of Brazil.
\end{abstract}

Keywords: Executive Secretariat. High Education. Distance Education. Brazil. 


\section{INTRODUÇÃO}

O primeiro Curso de Secretariado Executivo, no Brasil, foi criado em 1969, na Universidade Federal da Bahia, em Salvador, e reconhecido somente em 1998 (Ribeiro, 2002). Passados mais de 40 anos, e com a demanda por profissionais na área aumentando no mercado, surgiram novos cursos de Secretariado.

Assim, no ano de 2004, por meio do parecer 102/2004 e da resolução 3/2005, foi estabelecido pelo Ministério da Educação as Diretrizes Curriculares do Curso de Secretariado - DCN, que tem por objetivo padronizar o currículo de formação profissional nas Instituições de Ensino Superior - IES (Bilert \& Biscoli, 2011). Como todas as outras conquistas do secretariado, concretizou-se devido à luta de seus profissionais e à necessidade de adequações exigidas pelo mercado (Paes et al., 2015; Lobato, Caldas \& Costa, 2016).

Conforme os dados do Instituto de Pesquisa Econômica Aplicada (IPEA, 2013) que retratam as profissões que mais têm se expandido no Brasil, no período de janeiro de 2009 a dezembro de 2012, o curso de secretariado ocupou o quarto lugar entre as 22 ocupações de nível superior que mais geraram postos de trabalho no Brasil. Entretanto, foi identificado por meio dos relatórios do ENADE e do MEC evidências de um processo de retração na oferta de cursos de bacharelado na área (Cielo, Schmidt \& Wenningkamp, 2014). Contudo, a profissão de secretariado realmente não está desaparecendo do mercado, e sim, outras modalidades de formação na área estão em desenvolvimento, como é o caso dos cursos de tecnologia e os cursos de secretariado na modalidade a distância (Cielo, Schmidt \& Wenningkamp, 2014).

No Brasil, com o Decreto 5.622, em 2005 a modalidade de educação a distância obteve respaldo legal para sua realização com a Lei de Diretrizes e Bases da Educação - Lei 9.394/96 (MEC, 2015). A educação a distância é apresentada como o processo de ensinoaprendizagem onde alunos e professores se conectam por meio da tecnologia, possibilitando que sua separação espacial e/ou temporal não impeça a conexão e troca de conhecimento (Moran, 2002).

Neste contexto, com a padronização do currículo e a criação de cursos a distância, observa-se uma lacuna nos estudos científicos da área em relação aos cursos superiores de secretariado a distância no Brasil, no sentido de compreender o processo de crescimento e/ou permanência da demanda destes e sua relevância na manutenção da profissão.

Diante dessas reflexões e das lacunas identificadas, busca-se responder ao seguinte questionamento: Qual a realidade dos cursos de secretariado na modalidade a distância a nível Brasil? Assim, o objetivo geral desta pesquisa é conhecer a realidade dos cursos de secretariado, e suas variantes (Secretariado Executivo, Secretariado Executivo Bilíngue e Secretariado Executivo Trilíngue), na modalidade a distância - $\mathrm{EaD}$ - e dessa forma, analisar a tendência nos rumos do curso no Brasil. Logo, busca-se: a) identificar os cursos ativos de secretariado na modalidade presencial e a distância; b) relacionar as IES com os estados que disponibilizam os cursos de secretariado na modalidade a distância; e c) conhecer o papel das IES públicas para os cursos de secretariado a distância.

A metodologia utilizada na pesquisa foi quantitativa, sendo que a população se constituiu dos cursos de secretariado a distância ativos no Brasil, conforme informações coletadas no site emec.mec.gov.br, em dezembro de 2015. O conjunto de variáveis quantitativas foi representado e sintetizado em Tabelas e Figuras para a avaliação. Com o auxílio do software UCINET, redes foram criadas e disponibilizadas para a análise das relações existentes entre as IES e as UF's atendidas pelo curso na modalidade a distância. 
Para tanto, o texto está estruturado em cinco partes centrais, que se inicia com esta introdução. Na sequência faz-se uma descrição dos principais conceitos relacionados ao tema. Em seguida, descreve-se o método e os procedimentos da pesquisa. Após, descrevem-se os resultados do estudo e, por fim, apresentam-se as considerações finais e sugestões para estudos futuros sobre o tema.

\section{REFERENCIAL TEÓRICO}

A fim de conhecer a realidade dos cursos de secretariado a distância no Brasil, por meio das Instituições de Ensino Superior - IES -, foi revisado o contexto histórico do EaD e do curso de secretariado no país. Desta forma, o referencial teórico baseia-se em buscar a história do curso de secretariado no Brasil, bem como a trajetória do EaD no Brasil.

\subsection{A FORMAÇÃO DO PROFISSIONAL DE SECRETARIADO}

Ao que se refere a formação dos profissionais, o primeiro curso de secretariado executivo, no Brasil, foi criado em 1969, na Universidade Federal da Bahia, na cidade de Salvador, mas que foi reconhecido somente em 1998 (Ribeiro, 2002). Porém de acordo com a FENASSEC - Federação Nacional das Secretárias e Secretários (1998), o primeiro curso superior reconhecido no Brasil foi o da Universidade Federal de Pernambuco, criado em 1970 e reconhecido em 1978.

Um movimento representado por profissionais de secretariado, dirigentes das associações, sindicatos, coordenadores e alunos de graduação e dos cursos técnicos, conseguiu a aprovação do parecer CES/CNE 102/2004, de 11/03/2004, que passou a conter as diretrizes para o Curso de Secretariado Executivo (Nonato Júnior, 2009). Porém, apenas em 2005, foram instituídas as Diretrizes Curriculares Nacionais (DCN) do curso, documento este que passou a organizar o currículo dos cursos de graduação em secretariado executivo. Nonato Júnior (2009) ressalta que, a partir da DCN, ampliou-se a discussão do curso de secretariado executivo sobre o conhecimento nas assessorias, fortalecendo a formação acadêmica consistente e interdisciplinar.

Quanto à formação, a educação superior em secretariado abrange os cursos de graduação e os sequenciais. Os cursos de graduação são abertos a candidatos que tenham concluído o ensino médio ou equivalente, e conferem diploma aos concluintes, sendo classificados em: bacharelados, licenciaturas e cursos superiores de tecnologia (MEC, 2016). Os cursos tecnológicos suprem uma demanda do mercado por especialistas dentro de uma área de conhecimento, em vez dos generalistas formados pelas outras modalidades de ensino superior. Esse tipo de curso de graduação é orientado por características como foco, rapidez e flexibilidade. Os cursos superiores de tecnologia são, portanto, cursos distintos das graduações tradicionais - parecer CNE/CES no 436/2001, e seus concluintes ficam habilitados a prosseguir seus estudos em nível de pós-graduação (Takahashi, 2010).

Os cursos sequenciais são organizados por campo de saber, de diferentes níveis de abrangência, abertos a candidatos que atendam aos requisitos estabelecidos pelas IES, desde que tenham concluído o ensino médio ou equivalente. Podem ser de formação específica e/ou complementação de estudos (MEC, 2016).

Conforme a DCN, os cursos de secretariado executivo poderão admitir linhas de formação específicas, nas diversas áreas relacionadas, contidas no exercício das funções da profissão, para melhor atender às necessidades do perfil profissiográfico que o mercado ou a 
região exigem. Essa questão explica as diferentes nomenclaturas utilizadas pelas IES quanto à oferta do curso, que podem ser encontrados como: secretariado, secretariado executivo, secretariado executivo bilíngue e secretariado executivo trilíngue (MEC, 2015).

Paralelamente aos aspectos profissionais, a qualificação dos docentes em secretariado executivo é outro fator que pode ser mencionado como importante para a evolução da profissão. Apesar da inexistência de cursos de pós-graduação stricto sensu na área (Maçaneiro \& Kuhl, 2013), existe a preocupação dos professores em aumentar sua titulação e, consequentemente, ter possibilidades de melhorar a qualidade do ensino na graduação (Cielo, Schmidt \& Wenningkamp, 2014; Sabino \& Barrigões Gonçalves, 2016).

Diante disso, diversos fatores influenciaram positivamente o reconhecimento da profissão de secretário executivo, dentre eles: a regulamentação da profissão, a organização de entidades de classe, o código de ética, as diretrizes curriculares, os eventos científicos, maior envolvimento com pesquisa, os periódicos científicos, maior qualificação dos docentes, a criação de cursos de pós-graduação lato sensu e as exigências do mercado de trabalho (Cielo, Schmidt \& Wenningkamp, 2014). A criação da ABPSEC (Associação Brasileira de Pesquisa em Secretariado) também tem papel positivo no reconhecimento da profissão.

Conforme os dados do Instituto de Pesquisa Econômica Aplicada (IPEA, 2013) que retratam as profissões que mais têm se expandido no Brasil, no período de janeiro de 2009 a dezembro de 2012, o curso de secretariado ocupou o quarto lugar entre as 22 ocupações de nível superior que mais geraram postos de trabalho no Brasil. Esse mapeamento realizado também indica a predominância de vagas para profissionais de secretariado nos estados de Minas Gerais, Roraima e por toda a região Centro-Oeste (com exceção do Distrito Federal) (IPEA, 2013).

$\mathrm{Na}$ modalidade presencial, os cursos de secretariado no Brasil apresentaram um movimento de expansão nas últimas décadas, obtendo um crescimento de 32 para 113 cursos ofertados até 2007. Contudo, paralelamente os dados do ENADE demonstram que a cada ano um menor número de instituições participam desse exame com os cursos de secretariado, alertando para uma redução de $41,1 \%$ dos cursos presenciais no país (Cielo, Schmidt \& Wenningkamp, 2014).

Com dados que remetem a antiguidade da profissão, e toda a evolução que o curso e a profissão obtiveram no Brasil nas últimas 4 décadas, levantasse a discussão para um cenário de que o curso caminha para uma educação predominante a distância em todas as regiões do país.

\subsection{EVOLUÇÃO DA EDUCAÇÃO A DISTÂNCIA}

A educação a distância é apresentada como o processo de ensino-aprendizagem onde alunos e professores se conectam por meio da tecnologia, possibilitando que sua separação espacial e/ou temporal não impeça a conexão e troca de conhecimento. Neste contexto, quando se fala de tecnologia, considera-se o correio, o rádio, a televisão, o vídeo, o CD-ROM, o telefone, e a Internet (Moran, 2002).

Os principais elementos do $\mathrm{EaD}$ são: a distância física entre professor e aluno; o processo de ensino-aprendizagem mediatizado, ou seja, oferecer suporte e sistema que viabilize e incentive a autonomia do aluno no processo; o estudo individualizado e independente; a utilização de tecnologias; e a comunicação bidirecional (Preti, 1996). Diante disso, o grande desafio da $\mathrm{EaD}$ é provocar a participação ativa do aluno no processo de aprendizagem (Oliveira, 2015).

$\mathrm{O}$ EaD também proporciona aos alunos a possibilidade de interagir com os melhores 
professores do país ou até mesmo do mundo, podendo desenvolver assim um curso com alta qualidade. Desta forma o EaD tem a missão de formar novos pensadores, novos profissionais e capacitar as pessoas cada vez mais (Mattos \& Barbosa, 2015).

A maioria dos estudantes introduzidos neste processo são adultos inseridos no mercado de trabalho, que residem em locais distantes dos núcleos de ensino, e dispõem de pouco tempo para estudar no ensino presencial (Preti, 1996). Também fazem parte deste grupo as pessoas com deficiência física, que encontram obstáculos no ensino presencial (Nunes, 2009). Portanto, a educação a distância é uma ferramenta de inclusão social, de desenvolvimento econômico, que consegue transpor as barreiras presentes na educação presencial (Mattos \& Barbosa, 2015).

Ao final da década de 1980 e início dos anos 90, o desenvolvimento de sistemas de comunicação de fibra ótica permitiu a expansão no âmbito educativo de sistemas de áudio e vídeo ao vivo, bidirecionais e de alta qualidade. Com a introdução do uso de computadores e da internet, se ampliaram as possibilidades da $\mathrm{EaD}$, tornando possível a interação e o trabalho de colaboração entre os estudantes, e a fácil distribuição dos materiais dos cursos (Benetti, 2008).

No Brasil, com o Decreto 5.622, em 2005 a modalidade de educação a distância obteve respaldo legal para sua realização com a Lei de Diretrizes e Bases da Educação - Lei 9.394/96 - que estabelece no artigo 80 a possibilidade do uso do EaD em todos os níveis e modalidades de ensino (MEC, 2015). Assim, após a aprovação da LDB e, sobretudo, após 2001 com a norma que definiu que até $20 \%$ das disciplinas do curso presencial poderiam ser ofertadas na modalidade a distância, a possibilidade de ampliar a oferta de EaD foi concretizada, e esse novo espaço de ensino e aprendizagem virtual acelerou a utilização de EaD nas IES brasileiras (Pereira, 2010).

Em 2004, o INEP desenvolveu o SINAES - Sistema Nacional de Avaliação do Ensino Superior - que instituiu a avaliação das IES, de cursos e do desempenho dos estudantes de forma integrada (Pereira, 2010). Em 2007, esse instrumento de avaliação passou a ser utilizado pelo INEP para o credenciamento de instituições para oferta de EaD, credenciamento de pólos de apoio presencial e autorização de cursos na modalidade a distância (Pereira, 2010). Em sua origem, o SINAES previu três modalidades de avaliação: a avaliação realizada pelos atores internos das IES, a avaliação realizada pelo Banco de avaliadores do Sistema Nacional de Avaliação da Educação Superior e a avaliação de desempenho dos estudantes dos cursos de graduação por meio de provas e da formação geral e específica que compõem o Exame Nacional de Desempenho dos Estudantes (ENADE) (Lacerda \& Ferri, 2015).

O fato é que a partir de meados de 1990 o ensino a distância no Brasil vem crescendo, mesmo que a quantidade de matrículas, em números absolutos, ainda seja maior no ensino presencial (INEP, 2013). O modelo a distância tem se mostrado economicamente mais viável para as IES, por possibilitar a diluição dos custos por meio do rateio com os seus alunos espalhados por diversas partes do país (Mattos \& Barbosa, 2015). A criação de grandes parcerias, reunindo um número significativo de universidades para ofertar cursos através de uma rede de pólos de atendimento presencial, vem sendo o grande estimulador da expansão da EaD no país (Vilarinho \& Paulino, 2010).

Em termos instituicionais, a oferta de cursos superiores a distância poderia ser classificada dentro das seguintes três grandes tendências (Moran, 2002). O Quadro 2 apresenta as características de cada uma dessas tendências. 
Quadro 1 - Tendênciasdos cursos superiores a distância

\begin{tabular}{|c|l|}
\hline Tendência & \multicolumn{1}{c|}{ Característica } \\
\hline Instituições Isoladas & $\begin{array}{l}\text { Instituições que já atuam na educação presencial e agora oferecem } \\
\text { cursos a distância }\end{array}$ \\
\hline Associações ou Consórcios & $\begin{array}{l}\text { Derivam da união de IES que se mobilizam conjuntamente para oferecer } \\
\text { cursos a distância em vários níveis }\end{array}$ \\
\hline $\begin{array}{c}\text { Instituições Exclusivamente } \\
\text { Virtuais }\end{array}$ & São criadas exclusivamente para oferecer cursos a distância \\
\hline
\end{tabular}

Fonte: Adaptado de Moran (2002).

Esse formato colaborativo permite que as IES unam competências para um trabalho em rede, baseado no uso de tecnologias de informação e comunicação, evitando iniciativas duplicadoras, a dispersão de recursos e melhorando o acesso ao público. Em cada polo criado, as IES disponibilizam uma estrutura administrativo-pedagógica, que suporta e apoia as atividades dos orientadores acadêmicos, responsáveis pelo acompanhamento e orientação do processo de aprendizagem nos munícipios atendidos (Moran, 2002).

\section{METODOLOGIA}

No intuito de atender ao objetivo geral, o presente estudo se caracteriza como descritivo, pois busca descrever e analisar o cenário do curso de secretariado na modalidade a distância no contexto brasileiro, listando os cursos ofertados na modalidade e as instituições de ensino superior que o disponibilizam, com base em um levantamento transversal de dados, e com o auxílio de dados secundários (Hair Jr et al., 2005).

A população estudada compreende os cursos de secretariado da modalidade a distância, listados no site do MEC em 25 de dezembro de 2015, contemplados no Brasil (Malhotra, 2012). Utilizou-se como filtro apenas o nome do curso, sendo este composto por quatro diferentes variações: secretariado, secretariado executivo, secretariado executivo bilíngue, secretariado executivo trilíngue. Com isso, foram obtidos dados de cursos na modalidade presencial e a distância. Logo, identificou-se as IES que ofertam o curso de secretariado a distância no Brasil e também a localidade onde o curso é disponibilizado, informações que representam o foco desta pesquisa.

A coleta das informações foi realizada no mês de dezembro de 2015 a partir do portal emec.mec.gov.br. Optou-se pela utilização de dados secundários devido à disponibilidade de dados confiáveis, e que são de livre acesso à toda população (Hair Jr et al., 2005). O conjunto de informações coletadas foi representado e sintetizado em Tabelas e Figuras para melhor visualização e análise. Com o auxílio do software UCINET, redes foram criadas e disponibilizadas para a análise das relações existentes entre as IES, e os estados atendidos pelo curso na modalidade a distância no Brasil.

O Brasil é formado por 26 Estados e o Distrito Federal, totalizando 27 Unidades Federativas (UF`s). Essas 27 UF`s são formadas por 5.565 municípios e compreendem uma população de 190.732.694 pessoas, segundo o Censo do Instituto Brasileiro de Geografia e Estatística - IBGE - de 2010 (IBGE, 2016). Para melhor compreensão e análise dos dados utilizou-se da divisão já existente do país em cinco regiões, sendo elas: Região Norte (RO, AC, AM, RR, PA, AP, TO), Região Nordeste (MA, BA, SE, AL, PE, PB, RN, CE, PI), Região Sudeste (MG, SP, RJ, ES), Região Sul (SC, PR, RS) e Centro-Oeste (MS, MT, GO, DF) (IBGE, 2016).

A representação dos fenômenos e medição das variáveis pela estatística descritiva de frequência é apresentada a seguir, nos resultados e discussões. 


\section{ANÁLISE E DISCUSSÃO DOS RESULTADOS}

Nesta seção serão analisados os dados coletados, a fim de investigar a contribuição empírica aos objetivos, contrapondo-os com os teóricos estudados.

\subsection{CENÁRIO GERAL DO CURSO DE SECRETARIADO}

Conforme os dados fornecidos pelo MEC, abrangendo-se as modalidades presencial e a distância, o curso de secretariado em suas diferentes variações, está disponível em todas as Unidades Federativas do Brasil. Neste contexto, 143 IES são de origem privada e 26 são públicas, totalizando 169 IES que ofertam cursos de secretariado no Brasil (MEC, 2015). O mapeamento realizado do cenário do curso pode ser melhor compreendido na Tabela 1.

Tabela 1 - Panorama Geral dos Cursos de Secretariado no Brasil

\begin{tabular}{lcccc}
\hline Curso & \multicolumn{2}{c}{$\begin{array}{c}\text { Número de } \\
\text { Instituições }\end{array}$} & $\begin{array}{c}\text { Número de Estados } \\
\text { que ofertam o } \\
\text { curso }\end{array}$ \\
\cline { 2 - 4 } Secretariado & EaD & Presencial & & 27 \\
Sec. Executivo & 14 & 63 & 21 \\
Sec. Ex. Bilíngue & 1 & 80 & 10 \\
Sec. Ex. Trilíngue & 0 & 15 & 7 \\
\hline Total & 0 & 14 & \\
\hline Fonte: Adaptado de MEC (2015) & 15 & 172 & \\
\hline
\end{tabular}

Conforme Tabela 1, o número de instituições que ofertam o curso de secretariado presencial, totalizam 158, porém na tabela apresentasse o número 172, devido a oferta de mais opções do curso por instituição. Ademais, 15 instituições oferecem na modalidade a distância os cursos. Os cursos de secretariado são ofertados em três diferentes categorias: Tecnológico, Bacharelado e Sequencial. Contudo, na modalidade de educação a distância são ofertados apenas cursos superiores de Tecnologia, e sob a nomenclatura de secretariado e secretariado executivo. A modalidade presencial dispõe de todas as variações do curso.

A partir dos dados coletados, também foi possível elaborar um mapa que demonstra a situação geral da distribuição dos cursos de secretariado no país na modalidade presencial e a distância. Como o foco desta pesquisa é o ensino a distância, os mapas e redes criadas para esta modalidade serão melhor detalhados na seção seguinte, já as informações quanto ao ensino presencial foram sintetizadas na Figura 1. 
Figura 1 - Mapeamento dos cursos de Secretariado Presencial em

2015.

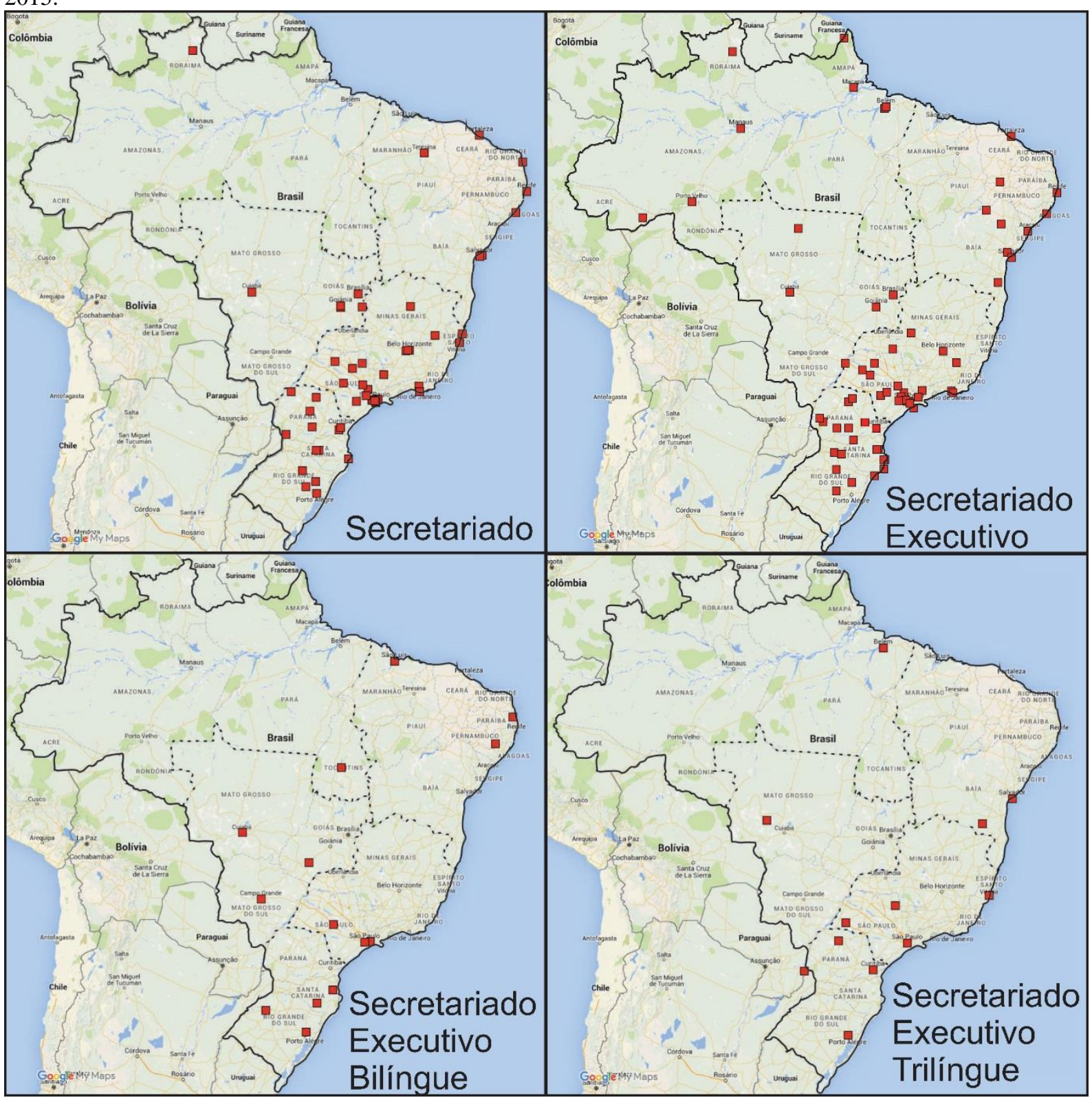

Fonte: Adaptado de MEC (2015)

Na Figura 1, as marcações vermelhas demonstram as cidades onde o curso está presente na modalidade presencial, de acordo com as diferentes nomenclaturas oferecidas. Cabe ressaltar que em alguns municípios há a oferta do curso por mais de uma IES. Contudo, tratam-se de poucos casos e por esse motivo optou-se por exibir as informações neste formato sintetizado, a fim de facilitar o entendimento geral do cenário.

Com base no panorama trazido pela literatura e pelos documentos analisados fica evidente que a expansão do curso seguiu um ritmo diferente do período anterior. Em 2007, haviam 113 cursos de secretariado na modalidade presencial (Cielo, Schmidt \& Wenningkamp, 2014). Em fevereiro de 2016, Sabino e Barrigão Gonçalves (2016) indicam os registros no site do E-MEC de 168 instituições que disponibilizavam os cursos de secretariado na modalidade presencial, porém para este estudo, levou-se em consideração o número de 158 
instituições, visto que a coleta foi realizada em dezembro de 2015. Com 158 instituições ofertando o curso em 2015, entendesse que houve um incremento na oferta brasileira.

\subsection{CURSOS DE SECRETARIADO NA MODALIDADE A DISTÂNCIA}

Conforme exposto, na modalidade a distância a oferta do curso restringe-se ao nível tecnológico sob a nomenclatura de secretariado e secretariado executivo. O curso de secretariado na modalidade a distância é ofertado em todas as UF's. Porém, o curso de secretariado executivo a distância tem sua oferta limitada aos estados de Minas Gerais (MG), Paraná (PR) e São Paulo (SP). Nesta relação oferecida pelo site do MEC, todos os cursos apresentam o status de ativos. Na Figura 2 encontram-se mapeados os cursos disponíveis na modalidade a distância em todo o Brasil.

\section{Figura 2 - Cursos de Secretariado EaD no Brasil}

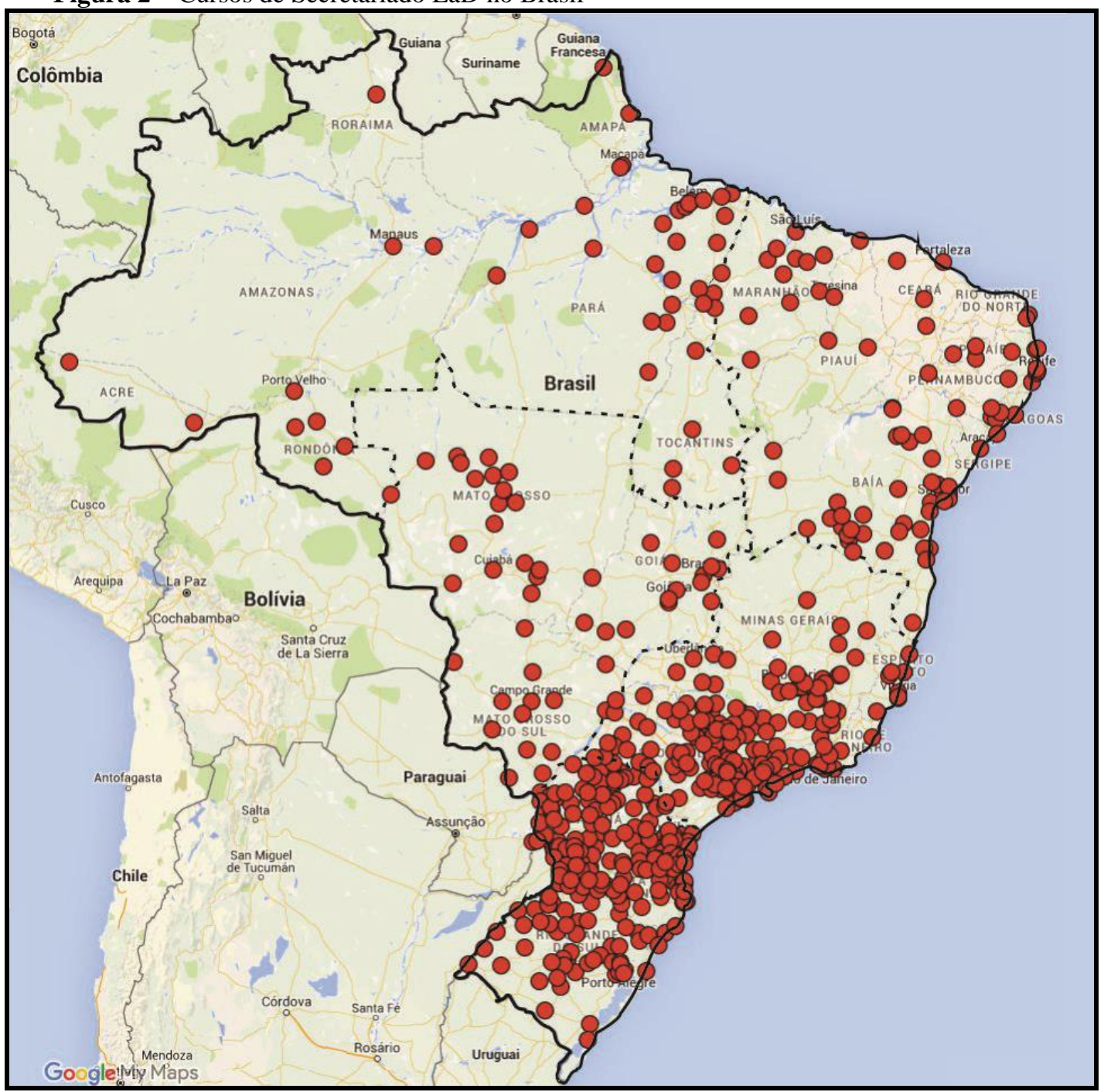

Fonte: Adaptado de MEC (2015)

Na Figura 2 os pontos vermelhos representam a presença do curso na modalidade a distância nos diversos municípios brasileiros. Apesar de presentes em todos os estados, 
observa-se que as regiões Sul e Sudeste são as de maior representatividade na quantidade de cursos ofertados, informação ratificada na Tabela 2.

Tabela 2 - Número de cursos EaD por região do Brasil

\begin{tabular}{l|r|r}
\hline Região & $\mathbf{N}^{\mathbf{0}}$ Cursos & \% por oferta \\
\hline Sul & 288 & $29,81 \%$ \\
Sudeste & 403 & $41,71 \%$ \\
Centro-Oeste & 87 & $9,03 \%$ \\
Norte & 66 & $6,83 \%$ \\
Nordeste & 122 & $12,62 \%$ \\
\hline Total & $\mathbf{9 6 6}$ & $\mathbf{1 0 0 \%}$
\end{tabular}

Fonte: Adaptado de MEC (2015)

Destacasse que os 966 cursos, representados na Tabela 2, são ofertados pelas 15 instituições apresentadas na Tabela 1. A representatividade na oferta de cursos nas regiões Sul e Sudeste na modalidade a distância (Tabela 2) é semelhante a retratada nos cursos na modalidade presencial (Figura 1). Ademais, na região norte do país, observa-se uma escassa oferta de cursos tanto nas modalidades presencial quanto a distância.

Logo, entende-se que o curso na modalidade a distância está competindo com os cursos na modalidade presencial, em se tratando de localidades onde o curso é ofertado em ambas as modalidades. Enquanto nesses estados existe uma disputa de vagas, a região norte sofre com a ausência da oferta do curso, tanto na modalidade presencial como a distância. A Figura 1 e a Tabela 2 também revelam o descaso com a região centro-oeste do país, que dispõe de um número reduzido de ofertas nas duas modalidades, situação semelhante à da região norte.

\subsubsection{Polos de ensino a distância}

A fim de melhor visualizar em quais localidades estão as IES que ofertam o curso de secretariado a distância foram criadas redes, nas quais é possível visualizar em quais UF's há polos e quais as instituições atuantes. As redes foram elaboradas de acordo com as regiões do Brasil, conforme demonstrado na Figura 3. 
Figura 3 - Redes de IES x UF

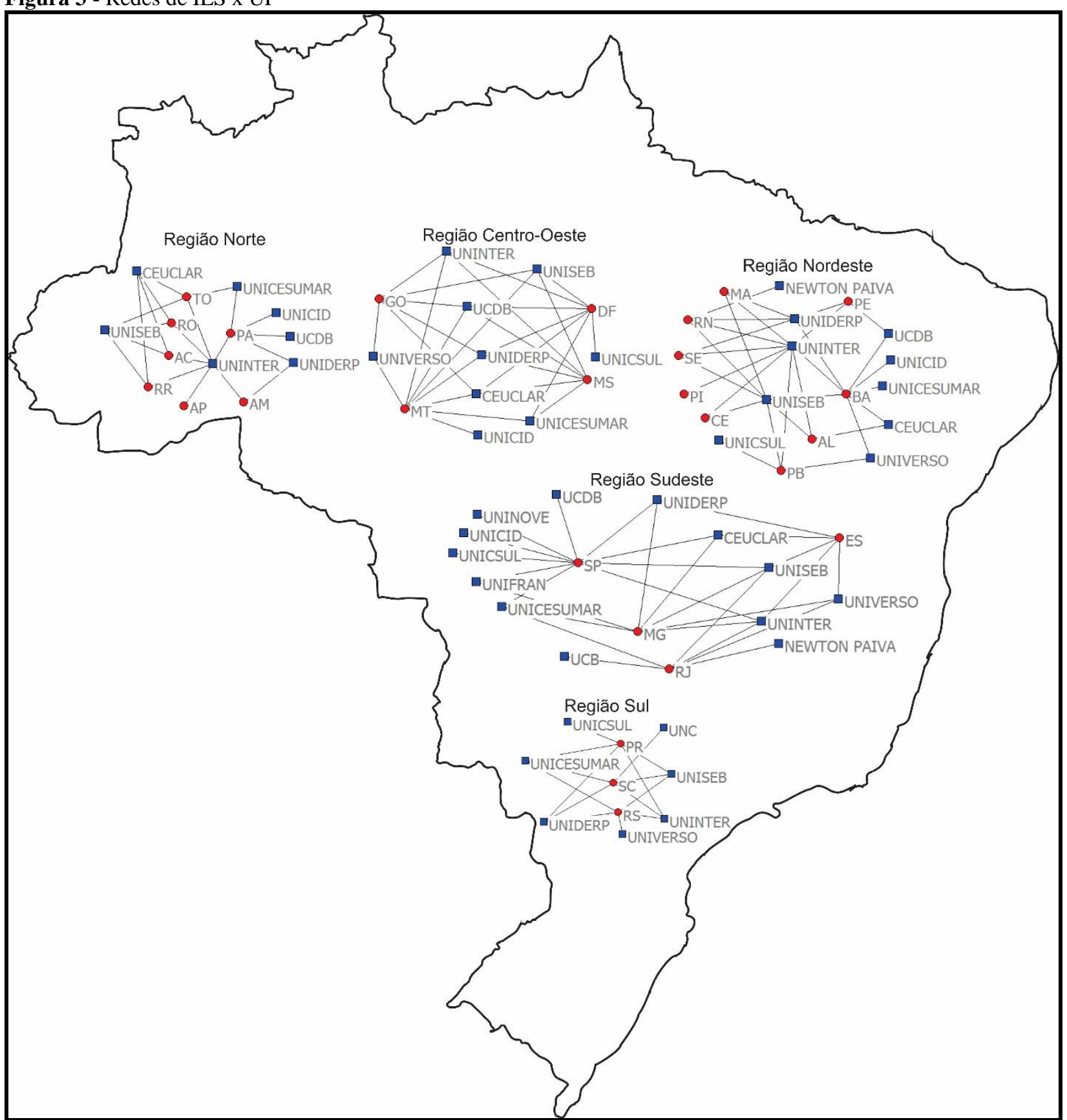

Fonte: Adaptado de MEC (2015)

Na Figura 3, observa-se o mapa do Brasil, separado conforme suas regiões, onde se formam as redes de oferta do curso na modalidade a distância. As marcações vermelhas representam as UF's brasileiras onde há a oferta do curso na modalidade a distância, enquanto que os pontos azuis demonstram as IES que ofertam o curso nessas localidades.

Nota-se a presença de um número restrito de IES atuando no curso de Secretariado a distância, num total de 15. Porém, a maior parte destas IES atuam em mais de uma UF da mesma região, o que caracteriza a criação de polos de atendimento. A região Sul é atendida por 8 IES, a região Sudeste por 13 IES, a região Centro-Oeste por 9 IES, a região Nordeste por 10 e a região Norte por 7 IES. No Quadro 2 está relacionada a sede das 15 IES que ofertam o curso de secretariado no Brasil. 
Quadro 2 - IES x Sede da IES x Natureza da IES x No de UF x Nº de cursos

\begin{tabular}{|c|c|c|c|c|}
\hline IES & Sede & Natureza da IES & $\begin{array}{l}\mathrm{N}^{\mathbf{0}} \mathrm{de} \\
\mathrm{UF}\end{array}$ & $\begin{array}{l}\mathbf{N}^{0} \text { de } \\
\text { Cursos }\end{array}$ \\
\hline UNINTER & PR & Sociedade Empresária Limitada & 27 & 534 \\
\hline UNISEB & SP & Sociedade Empresária Limitada & 22 & 115 \\
\hline UNIDERP & MS & Sociedade Empresária Limitada & 17 & 74 \\
\hline UNICESUMAR & PR & Sociedade Empresária Limitada & 12 & 61 \\
\hline UNICID & SP & Sociedade Empresária Limitada & 4 & 46 \\
\hline CEUCLAR & SP & Associação Privada & 15 & 35 \\
\hline UNIFRAN & SP & Sociedade Anônima Fechada & 2 & 23 \\
\hline UNIVERSO & RJ & Associação Privada & 8 & 20 \\
\hline UNC & $\mathrm{SC}$ & Fundação Privada & 1 & 17 \\
\hline UCDB & MS & Associação Privada & 8 & 13 \\
\hline UNINOVE & SP & Associação Privada & 1 & 9 \\
\hline UBC & SP & Sociedade Empresária Limitada & 3 & 8 \\
\hline UNICSUL & SP & Sociedade Anônima Fechada & 4 & 8 \\
\hline NEWTON PAIVA & MG & Sociedade Empresária Limitada & 2 & 2 \\
\hline UCB & $\mathrm{RJ}$ & Associação Privada & 1 & 1 \\
\hline
\end{tabular}

Fonte: Adaptado de MEC (2015)

O Quadro 2 identifica que as IES de maior representatividade em número de UF's atendidas são a UNINTER, UNISEB, UNIDERP, CEUCLAR e UNICESUMAR, sendo que essas IES ofertam cursos de secretariado em todas as regiões do Brasil. Cabe salientar também, a grande diferença no número de cursos ofertados, sendo que a UNINTER, oferece aproximadamente cinco vezes mais cursos que a segunda colocada no ranking (UNISEB). Também se evidencia o fato de que todas as IES que ofertam o curso nesta modalidade são de origem privada.

\section{CONCLUSÕES}

Por meio das informações coletadas foi possível elaborar um mapa que representa o panorama dos cursos de secretariado, na modalidade a distância no Brasil. Este panorama é constituído por um total de 603 municípios atendidos com os cursos de secretariado ou secretariado executivo na modalidade a distância, sendo que estes municípios estão distribuídos por todos os estados brasileiros. Conforme Sabino e Barrigão Gonçalves (2016) as IES, em sua totalidade, são privadas, não havendo nenhuma instituição pública que oferte os cursos de secretariado a distância no Brasil.

No mapeamento nota-se a presença de um número restrito de IES atuando no curso de secretariado a distância, num total de 15 . Os resultados no mapeamento desses cursos se contrapõem ao panorama das oportunidades profissionais disponibilizado pelo IPEA (2013), que identifica em Minas Gerais, Roraima e na região Centro-Oeste (com exceção do Distrito Federal), um maior número de vagas nesta profissão. Conforme os dados apresentados na Tabela 2, identifica-se que a região Norte e a região Centro-Oeste detêm juntas apenas $15,86 \%$ das ofertas do curso de secretariado na modalidade a distância. Essa relação sugere uma lacuna na oferta do curso em regiões com alto potencial empregador destes profissionais.

Quando se trata das IES de maior relevância na oferta do curso, observou-se que tanto no número de Unidades Federativas atendidas, como na quantidade de municípios onde há oferta do curso, são cincos instituições de ensino superior que se destacam: UNINTER, UNISEB, UNIDERP, CEUCLAR e UNICESUMAR. Essas cinco IES estão presentes em todas as regiões do Brasil. 
Os cursos ativos, a distância, mapeados neste estudo totalizam 966 (MEC, 2015). Percebe-se então, um grande aumento do número de cursos ofertados, devido ao ensino a distância, que totaliza um número aproximadamente seis vezes maior do que os presenciais, que são ofertados por 158 instituições. Os cursos ofertados na modalidade a distância são os de secretariado e secretariado executivo, sendo que as outras duas variações do curso (Secretariado Bilíngue e Trilíngue), não estão disponíveis nessa modalidade.

Diante dessas reflexões é possível iniciar uma discussão acerca da realidade dos cursos de secretariado na modalidade a distância no Brasil. Respondendo aos objetivos propostos, nota-se uma predominância de oferta de cursos de secretariado a distância. Porém, questionam-se os propósitos da educação a distância neste cenário, visto que em diversas localidades, há uma disputa de oferta entre as duas modalidades - presencial e a distância, e não a busca pela ampliação do atendimento ou pela redução de custos.

Entende-se, pelos dados analisados, que o curso de secretariado está migrando para o modelo de ensino a distância, na categoria tecnólogo, que exige um mínimo de 1.600 horas/curso, salvo pelos cursos que ofertam línguas (Bilíngue e Trilíngue). Ressalta-se que na categoria tecnólogo é exigida ao menos uma língua estrangeira, independentemente de ser na modalidade presencial ou a distância, enquanto o bacharelado dispõe de um maior número de horas curso (mínimo 2.400 horas) e pode, por consequência, acrescentar disciplinas de idiomas adicionais. Logo, identifica-se que os cursos bilíngue e trilíngue necessitam de um maior número de horas curso e por consequência estão restritos a modalidade presencial. (Sabino \& Barrigão Gonçalves, 2016)

Por meio desta pesquisa constatou-se que nenhuma IES teve a nota disponibilizada no site do MEC, o que impossibilita realizar qualquer análise da qualidade do ensino, representada pela nota do curso no ENADE. Uma das possíveis causas é a data de criação destes cursos, que pode ser recente, ou o site do MEC não estar atualizado.

Outro fator relevante é a inexistência de IES públicas que ofertam o curso na modalidade a distância, situação contraditória à realidade exposta. Esse cenário remete à reforma da educação superior brasileira, em que o estado com dificuldades de ampliar o número de vagas a curto e médio prazo nas IES públicas, passou a defender a ampliação da oferta por meio das IES privadas. Porém, os benefícios da educação a distância remetem a um trabalho colaborativo que permite que as IES unam competências para um trabalho em rede, evitando iniciativas duplicadoras, a dispersão de recursos e melhorando o acesso ao público (Moran, 2002). Logo, é incompreensível que o estado não se utilize da mesma estratégia que as IES privadas, a fim de garantir um direito público à educação superior, considerando que muitos profissionais não teriam condições de frequentar cursos presenciais (Preti, 1996).

Quanto as limitações, entende-se que o site utilizado para o levantamento das informações pode apresentar inconsistência e dados desatualizados, pois depende de as instituições de ensino atualizarem o sistema. Há, ainda, instituições e cursos em processo de encerramento e tal procedimento é lento, continuando, assim, com o status ativo na plataforma do EMEC. Portanto, as informações apresentadas neste artigo demonstram-se validas como ponto de partida para outros estudos. Ademais, refletem o problema existente quanto aos dados disponíveis para o estudo desta área.

Como estudos futuros, sugere-se que seja feita uma análise mais profunda, tomando como base este panorama geral. Recomenda-se também a utilização desta metodologia para outras áreas do saber. A criação de um panorama como este, pode vir a contribuir para o entendimento e o esclarecimento de questões importantes na área da educação e dos rumos da educação no Brasil. Cabe salientar que a criação e a comparação entre os cenários da educação a distância e presencial podem contribuir para a evolução da educação em nosso 
país, pois demonstram as localidades para ampliação das vagas e as cidades já cobertas pelas IES e pelos cursos superiores.

Por fim, sugere-se ainda, que estudos do tipo survey, sejam realizados com as IES tomando como base este panorama criado, a fim de contribuir ainda mais para o assunto. Entende-se que caberia também a exploração do tema sob uma abordagem qualitativa, o que permitiria o aprofundamento das análises.

\section{REFERÊNCIAS}

Benetti, K. C. (2008). Competências docentes para EAD: análise da realidade do curso de graduação em Administração a distância da Universidade Federal de Santa Catarina.

Bilert, V. S., \&Biscoli, F. V. (2011). Executive Secretariat Students' Profile (freshmenandseniors): A comparative studyinpubliceducationinstitutions. Revista de Gestão e Secretariado, 2(2), 33.

BRASIL. MEC, CNE. Resolução $n^{\circ}$. 3, de 23 de Junho de 2005. Institui as diretrizes curriculares para os cursos de graduação em Secretariado Executivo e dá outras providências. Brasília. $\quad 2005$ DF, Disponível em:< http://portal.mec.gov.br/cne/arquivos/pdf/rces003_05.pdf>. Acesso em: 11 fev. 2016.

Cielo, I. D., Schmidt, C. M., \& Wenningkamp, K. R. (2014). Secretariado Executivo no Brasil: Quo Vadis? Revista de Gestão e Secretariado, 5(3), 49.

FEDERAÇÃO NACIONAL DOS SECRETÁRIOS E SECRETÁRIAS - FENASSEC. (2015). Histórico da Profissão. Disponível <http://www.fenassec.com.br/b_osecretariado_historico.html>. Acesso em: 15 fev. 2016.

Hair Jr, J. F., Babin, B., Money, A. H., \&Samouel, P. (2005). Fundamentos de métodos de pesquisa em administração.Bookman.

INSTITUTO BRASILEIRO DE GEOGRAFIA E ESTATÍSTICA - IBGE. (2016). Estatísticas do Cadastro Central de Empresas ano 2009. Rio de Janeiro: IBGE.

INSTITUTO NACIONAL DE ESTUDOS E PESQUISAS EDUCACIONAIS - INEP. (2014). Censo da educação superior 2012: resumo técnico. Brasília, DF: Instituto Nacional de Pesquisas Educacionais Anísio Teixeira, 133.

INSTITUTO DE PESQUISA ECONÔMICA APLICADA - IPEA. (2013). Radar: tecnologia, produção e comércio exterior 2009-2012. Diretoria de Estudos e Políticas Setoriais, de Inovação, Regulação e Infraestrutura. Brasília, n. 1.

Lacerda, L. L. V. d., \& Ferri, C. (2015). Relationships between teaching quality indicators and student performance in Brazilian undergraduate courses of Pedagogy in the National Student Performance Exam (Enade). Revista Brasileira de Estudos Pedagógicos, 96(242), P.129-145. 
Lobato, M. G. S., Caldas, Y. P., \& Costa, A. J. S. (2016). Mercado de Trabalho e Empregabilidade sob a Lógica do Capital: Representações Sociais do Secretário Executivo no Amapá. Revista de Gestão e Secretariado, 7(1), P.01-26.

Lourenço, F., Moreira, K. D., \& Martins, C. (2014). Panorama do mercado de trabalho catarinense para o profissional de secretariado. In: Anais do VII Encontro Nacional de Estudantes de Secretariado, Salvador, BA, Brasil.

Maçaneiro, M. B., \& Kuhl, M. R. (2013). State of the art and the direction of scientific knowledge in the executive secretariat: Mapping and analysis of research areas. Revista de Gestão e Secretariado, 4(3), 157.

Malhotra, N. K. (2012). Pesquisa de Marketing: uma orientação aplicada. Porto Alegre: Bookman.

Mattos, J. E. G., \& Barbosa, D. M. F. (2015). Educação a distância: desafios no ensino superior. Maiêutica-Cursos de Gestão, 3(1)

MINISTÉRIO DA EDUCAÇÃO - MEC. (2015). Portal do MEC. Disponível em:< http://portal.mec.gov.br/. Acesso em 25 de dezembro de 2015.

Moran, J. M. (2002). A educação superior a distância no Brasil. São Paulo: USP.

Moreira, K. D., dos Santos, A. K., \& Neto, L. M. (2015). Profissional de Secretariado Empreendedor: Um Agente de Mudança. Revista de Gestão e Secretariado, 6(1), 168.

Neves, M. d. C. d. O. (2008). Introdução ao secretariado executivo. Rio de Janeiro: Tmaisoito.

Nonato Júnior, R. (2009). Epistemologia e teoria do conhecimento em secretariado executivo: a fundação das ciências da assessoria. Fortaleza: Expressão Gráfica.

Nunes, I. B. (2009). A história do EaD no Mundo. In: LITTO, F.; FORMIGA, M. (Org.). Educação a distância: o estado da arte. São Paulo, SP: Pearson Education do Brasil. P. 2-9

Oliveira, A. C. B. (2015). Ensino à distancia: novas práticas pedagógicas, novas habilidades de aprendizado. Paper presented at the $6^{\circ}$ Seminário Nacional do EDaPECI.

Paes, R. V. O., de Souza Antunes, C. K., da Silva Santiago, C., \& Zwierzikowski, M. R. (2015). Novas Formas de Atuação do Profissional de Secretariado Executivo. Revista de Gestão e Secretariado, 6(1), 99.

Pereira, J. M. (2008). Políticas públicas de educação no Brasil: a utilização da EAD como instrumento de inclusão social. Journal of Technology Management and Innovation, 3, P. 4455.

Preti,O. (1996). Educação a Distância: uma prática educativa mediadora $e$ mediatizada.NEAD/IE/UFMT. Cuiabá: UFMT. 
Ribeiro, N. D. L. A. (2002). Secretariado: do escriba ao gestor: um estudo sobre o novo perfil do profissional de secretariado. São Luis: Edfama.

Sabino, R. F., \& Barrigão Goncalves, V. M. (2016). The higher education to the secretaries in luso-brazilian perspective. Revista de Gestão e Secretariado, 7(1), 150-171.

Sabino, R. F., \& Rocha, F. G. (2004). Secretariado: do escriba ao webwriter- a história, a evolução e as novas competências do secretariado do $3^{\circ}$ milênio. Rio de Janeiro: Brasport.

Takahashi, A. R. W. (2010). Cursos superiores de tecnologia em gestão: reflexões e implicações da expansão de uma (nova) modalidade de ensino superior em administração no Brasil. Revista de administração pública, 44(2), 385-414.

Vilarinho, L. R. G., \& Paulino, C. L. (2010). Educação a Distância no Ensino Superior Brasileiro: das experiências pioneiras ao sistema de rede.Revista Eletrônica de Educação, 4(1), 64-79. 